\title{
CXCL12 modulates the radiosensitivity of cervical cancer by regulating CD44
}

\author{
ZHICHAO FU ${ }^{1,2^{*}}$, PEI ZHANG ${ }^{3 *}$, HUACHUN LUO $^{2}$, HUIJUAN HUANG ${ }^{4,5}$ and FENGMEI WANG ${ }^{4,5}$ \\ ${ }^{1}$ Department of Radiation Oncology, Dongfang Hospital, Xiamen University; ${ }^{2}$ Department of Radiation Oncology, \\ Fuzhou General Hospital of Nanjing Military Command, Fuzhou, Fujian 350025; ${ }^{3}$ Department of Radiation Medicine, \\ Faculty of Naval Medicine, Second Military Medical University, Shanghai 200433; ${ }^{4}$ Department of Gynaecology and Obstetrics, \\ Dongfang Hospital, Xiamen University; ${ }^{5}$ Department of Gynaecology and Obstetrics, Fuzhou General Hospital of \\ Nanjing Military Command, Fuzhou, Fujian 350025, P.R. China
}

Received December 21, 2017; Accepted July 13, 2018

DOI: $10.3892 / \mathrm{mmr} .2018 .9554$

\begin{abstract}
The aim of the present study was to investigate the regulation of stromal cell-derived factor 1 (CXCL12) in the radioresistance of cervical cancer, which was upregulated in tumors in our previous study. A CCK-8 assay was used to detect cell viability. Flow cytometry was used to measure cell apoptosis and the expression levels of CD44 and CXCR4. ELISA was performed to measure the expression level of CXCL12 protein and CXCL12 mRNA was detected by reverse transcription-quantitative polymerase chain reaction assays. Cell viability and apoptosis were determined with or without treatment with CXCL12 small interfering (si)RNA to examine the function of CXCL12 in Hela cells. The expression level of CD44 antigen (CD44) and C-X-C chemokine receptor type 4 (CXCR4) were measured using flow cytometry in the presence of CXCL12 and irradiation. In the present study, it was demonstrated that inhibition of CXCL12 reduced cell viability and increased cellular apoptosis in Hela cells treated with irradiation. Following treatment with CXCL12 siRNA, the expression level of CD44 was downregulated and the expression level of CXCR4 was upregulated. This effect of regulation additionally occurred in the presence of irradiation. In conclusion, the present data demonstrated that CXCL12 served an important role in the radioresistance of cervical cancer, suggestinh a novel therapeutic target.
\end{abstract}

Correspondence to: Professor Huijuan Huang or Professor Fengmei Wang, Department of Gynaecology and Obstetrics, Dongfang Hospital, Xiamen University, 156 West Second Ring North Road, Fuzhou, Fujian 350025, P.R. China

E-mail: 14404812@qq.com

E-mail: carnation1112@163.com

${ }^{*}$ Contributed equally

Key words: stromal cell-derived factor 1, CD44 antigen, radiosensitivity, cervical cancer

\section{Introduction}

Cervical cancer is the second most common type of malignant tumor in women (1). Radiotherapy remains the most effective therapeutic method for cervical cancer $(2,3)$. The recent rapid development of radiotherapy and novel targeted drugs has provided increasing treatment options for patients with cervical cancer. However, clinical outcomes have only improved slightly, due to the recurrence and metastasis of cervical cancer primarily resulting from radioresistance (4).

Previous studies demonstrated that the tumor microenvironment in cervical cancer is one of the factors that result in radioresistance. Alterations in the tumor microenvironment, where the tumor cells develop, affect the outcomes of radiotherapy $(5,6)$. Tumor cells regulate the microenvironment by releasing extracellular signals, and the tumor environment serves an important role in tumorigenesis, tumor growth, invasion, metastasis and angiogenesis (7). However, the underlying mechanisms between radioresistance and the tumor microenvironment in cervical cancer remain unclear. In our previous study, a microarray analysis was performed to identify genes associated with the tumor microenvironment in radioresistant tissues of cervical cancer (8). Stromal cell-derived factor 1 (CXCL12) and CD44 antigen (CD44) were identified as two important associated genes in the present study, and CXCL12 was additionally identified to be a negative factor in the prognosis of patients with cervical cancer following radical radiotherapy. According to a previous study, the binding of CXCL12 and its receptor, C-X-C chemokine receptor type 4 (CXCR4), serve an important role in tumor survival and development (9). Fuchs et al (10) reported that the binding of CD44 and CXCR4 in the presence of CXCL12 was able to activate the extracellular signal-regulated kinase (ERK) signaling pathway and increase cell motility in HepG2 cells and primary human umbilical vein endothelial cells. Recently, a number of studies reported that CXCL12 and CXCR4 mediate resistance to radiotherapy. Goffart et al (11) documented that CXCL12 mediates glioblastoma resistance to radiotherapy and Wang et al (12) demonstrated that CXCL12/CXCR4 serve important roles in the radioresistance of colorectal cancer cells. Therefore, CXCL12 and CXCR4 may contribute to radioresistance in a CD44-dependant manner in cervical cancer. In the 
present study, the underlying mechanisms via which CXCL12 regulates radioresistance through $\mathrm{CD} 44$ in cervical cancer were examined.

\section{Materials and methods}

Cell culture. The human cervical cancer (Hela) cell line (American Type Culture Collection, Manassas, VA, USA) was maintained in minimum essential medium (Gibco; Thermo Fisher Scientific, Inc., Waltham, MA, USA) containing 10\% fetal bovine serum (Gibco; Thermo Fisher Scientific, Inc.), $100 \mathrm{U} / \mathrm{ml}$ streptomycin and $100 \mathrm{U} / \mathrm{ml}$ penicillin in a humidified cell incubator with an atmosphere of $5 \% \mathrm{CO}_{2}$ at $37^{\circ} \mathrm{C}$.

Irradiation. In total, $60 \mathrm{Co}-\gamma$ rays in the irradiation center (Faculty of Naval Medicine, Second Military Medical University, Shanghai, China) were used for irradiation. Cells were exposed to different irradiation doses ( 4 and $8 \mathrm{~Gy}$ ) at a dose rate of $1 \mathrm{~Gy} / \mathrm{min}$ depending on the requirements of the present study.

Small interfering (si)RNA design and synthesis. siRNA $(50 \mathrm{nM})$ was used to downregulate the expression level of CXCL12 and nonsense siRNA was used as a negative control. All synthetic RNA sequences were designed, synthesized and purified by Sangon Biotech Co., Ltd., Shanghai, China. siRNAs used in the present study are presented in Table I.

Transfection. Lipofectamine ${ }^{\circledR} 2000$ (Invitrogen; Thermo Fisher Scientific, Inc.; cat. no. 11668-019) transfection reagent was used to perform transfection in Hela cells, which were seeded in 6-well plates at a density of $1 \times 10^{6}$, according to the manufacturer's protocol, as described previously (13). At $48 \mathrm{~h}$ post-transfection, cells were subjected to further experiments.

Cell viability assay. Cell viability was measured using a Cell Counting Kit-8 (CCK-8) assay (Dojindo Molecular Technologies, Inc., Kumamoto, Japan; cat. no. CK04). In total, $100 \mu \mathrm{l}$ cell suspension $(5,000$ cells/well $)$ was seeded in a 96-well plate. After $24 \mathrm{~h}$ of pre-incubation, cells were immediately irradiated. Following irradiation, cells were incubated for another $24 \mathrm{~h}$. Subsequently, CCK-8 solution was added to each well of the plate. The plate was incubated for $2 \mathrm{~h}$. The absorbance was measured at $450 \mathrm{~nm}$ using a microplate reader (Thermo Fisher Scientific, Inc.).

Apoptosis assay. At $24 \mathrm{~h}$ post-irradiation, cells were trypsinized and collected. The apoptosis of cells was determined by double-staining with Annexin V-fluorescein isothiocyanate and propidium iodide using an Apoptosis Detection kit (Invitrogen; Thermo Fisher Scientific, Inc.; cat. no. 88-8005), and analyzed using a flow cytometer (CytoFLEX; Beckman Coulter, Inc., Brea, CA, USA). Data were collected and analyzed using CytExpert (version 1.2.11.0; Beckman Coulter, Inc.).

Flow cytometry analysis. To determine the expression levels of CD44 and CXCR4 in Hela cells, cells were collected and stained with CD44-phycoerythrin (PE; $2 \mu \mathrm{g} / \mathrm{ml}$; eBioscience without blocking; Thermo Fisher Scientific, Inc.; cat. no. 12-0441-82) or CXCR4-PE ( $2 \mu \mathrm{g} / \mathrm{ml}$; eBioscience; Thermo Fisher Scientific, Inc.; cat. no. 12-9991-82). Cells were incubated in the dark
Table I. CXCL12-siRNA sequences.

\begin{tabular}{ll}
\hline CXCL12-siRNA & \multicolumn{1}{c}{ Sequence (5'-3') } \\
\hline si-RNA1 & Sense, CACGUAGCAGCUUAGACUA \\
& dTdT \\
& Antisense, UAGUCUAAGCUGCUACG \\
& UGdTd \\
si-RNA2 & Sense, CAGUGAAUGAUUCAGUGU \\
& UdTdT \\
& Antisense, AACACUGAAUCAUUCA \\
& CUGdTd \\
si-RNA3 & Sense, CACGUAGAACUUGGAUGU \\
& AdTdT \\
& Antisense, UACAUCCAAGUUCUAC \\
Nonsense & GUGdTdT \\
siRNA & Sense, UUCUCCGAACGUGUCACGU \\
& dTdT \\
& Antisense, ACGUGACACGUUCGGAG \\
& AAdTdT
\end{tabular}

CXCL12, stromal cell-derived factor 1; siRNA, small interfering RNA.

Table II. Primer sequences.

\begin{tabular}{lll}
\hline Gene & \multicolumn{1}{c}{ Forward (5'-3') } & \multicolumn{1}{c}{ Reverse (5'-3') } \\
\hline CXCL12 & GAAGTGGAGCCAT & TCCAAGTGGAA \\
\multirow{3}{*}{ GAPDH } & AGTAATGCC & AAATACACCG \\
& ATGACATCAAGA & CATACCAGGAA \\
& AGGTGGTG & TGAGCTTG
\end{tabular}

CXCL12, stromal cell-derived factor 1.

at room temperature for $20 \mathrm{~min}$. Following incubation cells were washed using PBS and subsequently subjected to flow cytometry analysis. Data were collected and analyzed using CytExpert (version 1.2.11.0; Beckman Coulter, Inc.).

ELISA. The expression level of CXCL12 in the supernatants of cell cultures was determined by ELISA. At $48 \mathrm{~h}$ following treatment, the supernatants of cell cultures were collected following centrifugation at $1,000 \mathrm{x}$ g for $10 \mathrm{~min}$ at room temperature. Subsequently, supernatants were subjected to ELISA, according to the manufacturer's protocol (BioVision, Inc., Milpitas, CA, USA; cat. no. K4387-100).

Reverse transcription-quantitative polymerase chain reaction $(R T-q P C R)$. Expression levels of RNA were quantified using RT-qPCR. Total cellular RNA was isolated with TRIzol ${ }^{\circledR}$ reagent (Invitrogen; Thermo Fisher Scientific, Inc.), according to the manufacturer's protocol. RNA was suspended in DNase/RNase free water, and RNA quantity and quality were determined at 260/280 nm using a spectrophotometer (Pharmacia Biochrom GeneQuant, Biochrom, Ltd., Cambridge, UK). Following the manufacturer's protocol, RNA was reverse transcribed into 

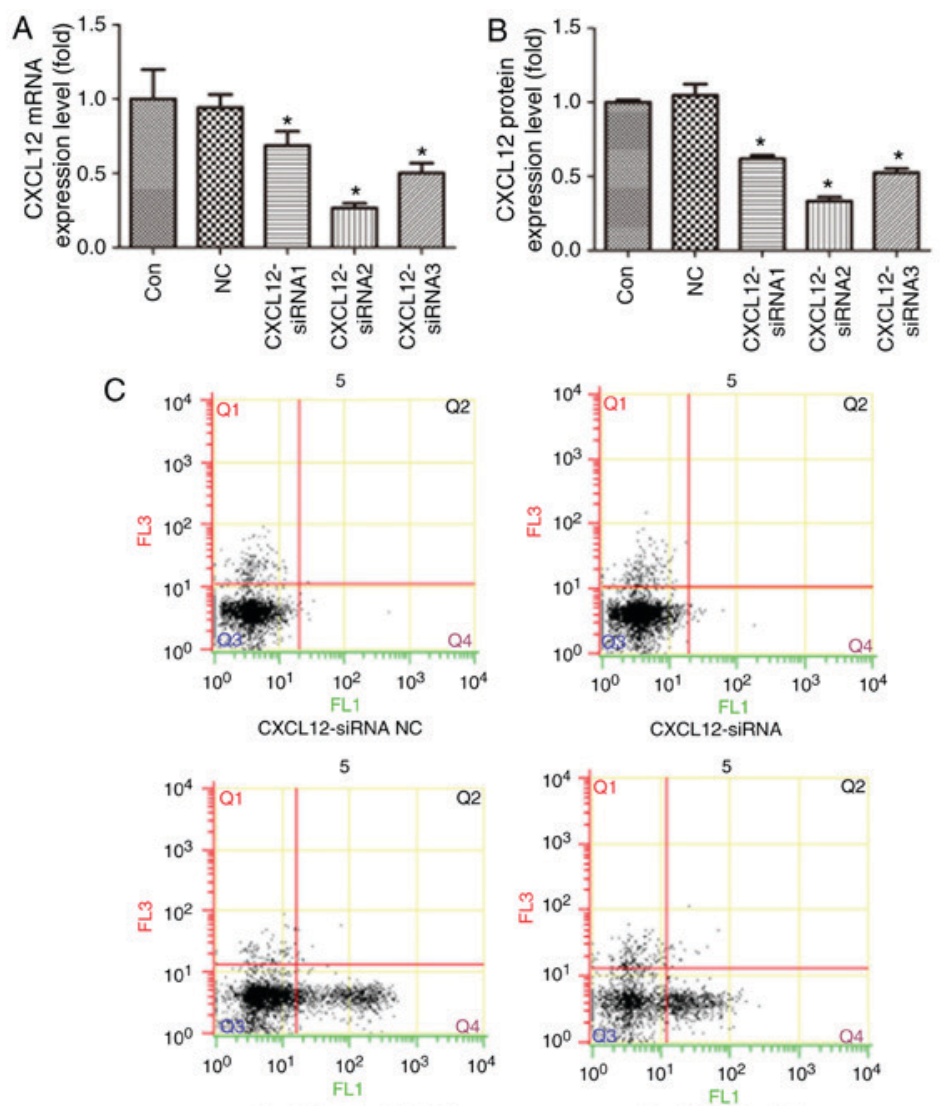

4Gy+CXCL12-SiRNA NC
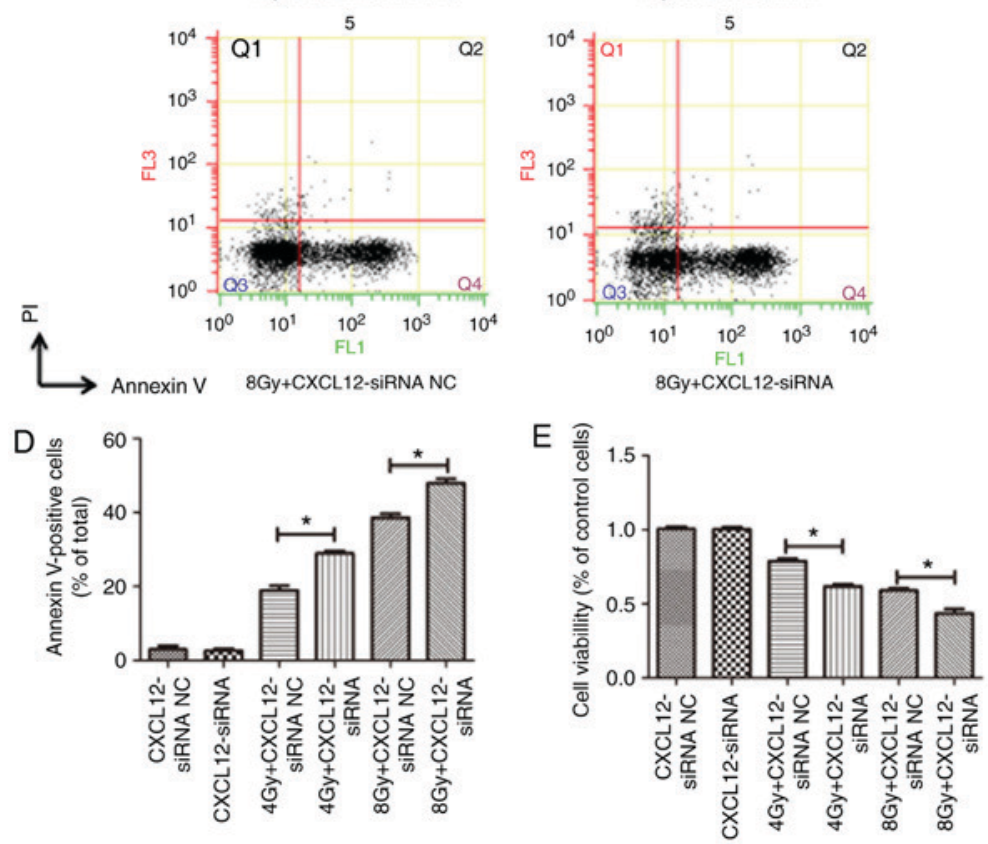

Figure 1. Inhibition of CXCL12 reduces cell viability and increases apoptosis in irradiated Hela cells. (A) siRNAs were used to downregulate CXCL12. CXCL12 mRNA expression was measured using a quantitative polymerase chain reaction $24 \mathrm{~h}$ post-treatment. (B) CXCL12 expression was determined using ELISA 48 h post-treatment. (C) Apoptotic cells were determined. (D) A bar graph of apoptotic cells expressed as a percentage of the total cells. (E) Cell viability was determined $24 \mathrm{~h}$ post-irradiation. Data are presented as the mean \pm standard error of the mean. $\mathrm{n}=3$. ${ }^{*} \mathrm{P}<0.05$ vs. respective NC group. si, small interfering; CXCL12, stromal cell-derived factor 1; NC, negative control; Con, control; PI, propidium iodide.

cDNA using an RT-PCR kit (Takara Biotechnology Co., Ltd., Dalian, China; cat. no. RR036A). The reverse transcription protocol was as follows: Three cycles at $37^{\circ} \mathrm{C}$ for $15 \mathrm{~min}$ (reverse transcription), and $85^{\circ} \mathrm{C}$ for $5 \mathrm{sec}$ (inactivation of reverse transcriptase with heat treatment). PCR was performed using SYBRGreen (Takara Biotechnology Co., Ltd., Dalian, China: cat. no. RR420A). Thermocycling conditions were as follows: Holding stage, $95^{\circ} \mathrm{C}$ for $30 \mathrm{sec}$; cycling stage, 40 Cycles of $95^{\circ} \mathrm{C}$ for $5 \mathrm{sec}$ and $60^{\circ} \mathrm{C}$ for $30 \mathrm{sec}$; and melt curve stage. The relative mRNA expression levels were calculated using the $2^{-\Delta \Delta C q}$ method (14). GAPDH was used as the reference. Primers used in the present study are presented in Table II. 
Statistical analysis. Data are presented as the mean \pm the standard error of mean for each experiment. The number of samples is indicated in the description of each experiment. One-way analysis of variance was conducted followed by a Student-Newman-Keuls post hoc test for statistical analysis. Experiments for quantification were conducted in a blind tests and all the experiments were repeated at least three independent times. Data were analyzed using SPSS ver. 19 (IBM Corp., Armonk, NY, USA).

\section{Results}

siRNA downregulates CXCL12 expression. To downregulate the expression level of CXCL12, RNA interference was performed. A total of three different designed siRNAs and nonsense siRNA were transfected into Hela cells. At $24 \mathrm{~h}$ post-transfection, the mRNA expression level of CXCL12 was measured using RT-qPCR (Fig. 1A). ELISA was performed on cell supernatants $48 \mathrm{~h}$ post-transfection to measure the protein expression level of CXCL12 (Fig. 1B). The mRNA and protein expression levels of CXCL12 were decreased significantly in the presence of the three designed siRNA $(\mathrm{P}<0.05)$. CXCL12 expression levels were lowest in the cells treated with CXCL12-siRNA2. Therefore, CXCL12-siRNA2 was used in the further experiments.

Cells treated with CXCL12 siRNA2 or nonsense siRNA receive 4 and 8 -Gy irradiation. At $24 \mathrm{~h}$ post-irradiation, cell viability was measured. It was demonstrated that the percentage of apoptotic cells increased with the downregulation of CXCL12 (Fig. 1C and D). Additionally, the downregulation of CXCL12 significantly decreased the cell viability of irradiated cells (Fig. 1E; P<0.05).

Irradiation increases CXCL12 in Hela cells. The expression level of CXCL12 was measured at $24 \mathrm{~h}$ post-irradiation with 4 Gy. As presented in Fig. 2, irradiation significantly upregulated the expression level of CXCL12 $(\mathrm{P}<0.01)$. However, CXCL12 expression levels were significantly decreased in the cells treated with CXCL12 siRNA compared with the irradiated cells $(\mathrm{P}<0.05)$.

Inhibition of CXCL12 decreases the CD44 expression level and increases the CXCR4 expression level. To examine the regulation of CXCL12 on CD44, CD44 expression levels were determined in Hela cells treated with or without CXCL12 siRNA. It was demonstrated that inhibition of CXCL12 significantly downregulated the expression of CD44 (Fig. 3A; $\mathrm{P}<0.05)$. However, the expression level of CXCR4 was significantly upregulated in the presence of CXCL12 siRNA (Fig. 3B; $\mathrm{P}<0.05$ ).

Inhibition of CXCL12 downregulates the expression level of CD44 in irradiated Hela cells. To examine the regulation of CXCL12 on CD44 in the presence of irradiation, Hela cells were irradiated at a dose of 4 and 8 Gy with or without treatment with CXCL12 siRNA. Following irradiation, the expression level of CD44 was measured. As demonstrated in Fig. 4, the expression level of CD44 was significantly increased with the irradiation in a dose-dependent manner $(\mathrm{P}<0.05)$.

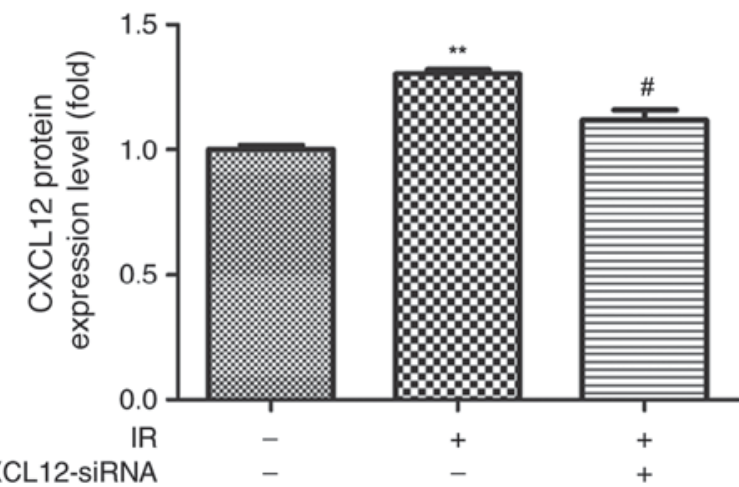

Figure 2. Irradiation upregulates the CXCL12 expression level in Hela cells. A bar graph of the CXCL12 expression level in Hela cells in the presence of irradiation, with or without treatment with CXCL12 siRNA, is presented. Data are presented as the mean \pm standard deviation. $n=3 .{ }^{* *} \mathrm{P}<0.05$ vs. control; ${ }^{\#} \mathrm{P}<0.05$ vs. IR. CXCL12, stromal cell-derived factor 1 ; siRNA, small interfering RNA; IR, irradiation.

However, less of an increase was observed in irradiated Hela cells treated with CXCL12 siRNA (Fig. 4).

Inhibition of CXCL12 upregulates the expression level of CXCR4 in irradiated Hela cells. To investigate the regulation of CXCL12 on CXCR4 in the presence of radiation, the expression level of CXCR4 was additionally determined following irradiation. It was demonstrated that CXCR4 was upregulated in the presence of CXCL12 siRNA in irradiated Hela cells (Fig. 5).

\section{Discussion}

The tumor microenvironment, in which tumor cells develop, is composed of tumor cells, stromal cells, capillaries, tissue fluids and a few infiltrating cells, including dendritic cells and macrophages, which serve an important role in the growth, invasion and metastasis of tumor cells (15). With the developments in cancer research, the tumor microenvironment has raised widespread concern in recent years. Numerous previous studies have reported that the response of tumor cells to radiotherapy is affected by a number of factors in the tumor microenvironment $(15,16)$.

In our previous study (8), an oligonucleotide microarray was used to identify the differentially expressed genes in residual cervical cancer following radiotherapy. As a result, 111 genes were identified to be upregulated and 127 genes were downregulated following a 50-Gy dose of radiation compared with the control group (8). Among all these differentially expressed genes, the expression level of CXCL12 was the highest, according to the validation of the microarray data with qPCR. The expression of CXCL12 was detected with immunohistochemistry on 130 paraffin embedded samples, and it was identified that the percentage of CXCL12-positive cells was $\sim 61.5 \%$ (8). Furthermore, a Kaplan-Meier survival analysis revealed that CXCL12 was an independent risk factor and was strongly correlated with poor prognosis (8). The present data suggested that CXCL12 served an important role in the radioresistance of cervical cancer. Recently, numerous studies demonstrated that the CXCL12/CXCR4 axis mediates 

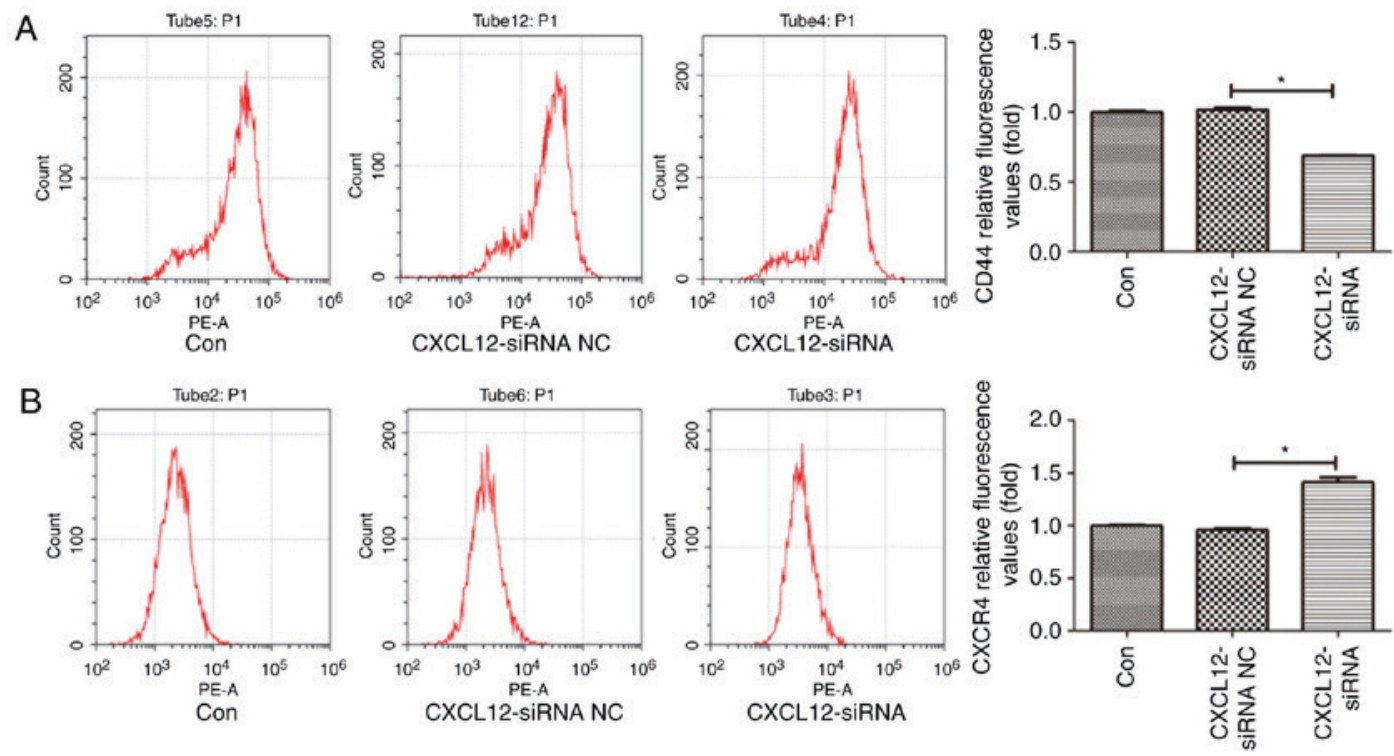

Figure 3. Inhibition of CXCL12 decreases the CD44 expression level and increases the CXCR4 expression level. The expression level of CD44 was measured using flow cytometry. (A) CD44 fluorescence in cells treated with or without CXCL12 siRNA. The expression level of CXCR4 was additionally determined by flow cytometry. (B) CXCR4 fluorescence in cells treated with or without CXCL12 siRNA. Data are presented as the mean \pm standard deviation. $\mathrm{n}=3$. " $\mathrm{P}<0.05$. CXCL12, stromal cell-derived factor 1; CD44, CD44 antigen; siRNA, small interfering RNA; NC, negative control; Con, control; PE, phycoerythrin; CXCR4, C-X-C chemokine receptor type 4.
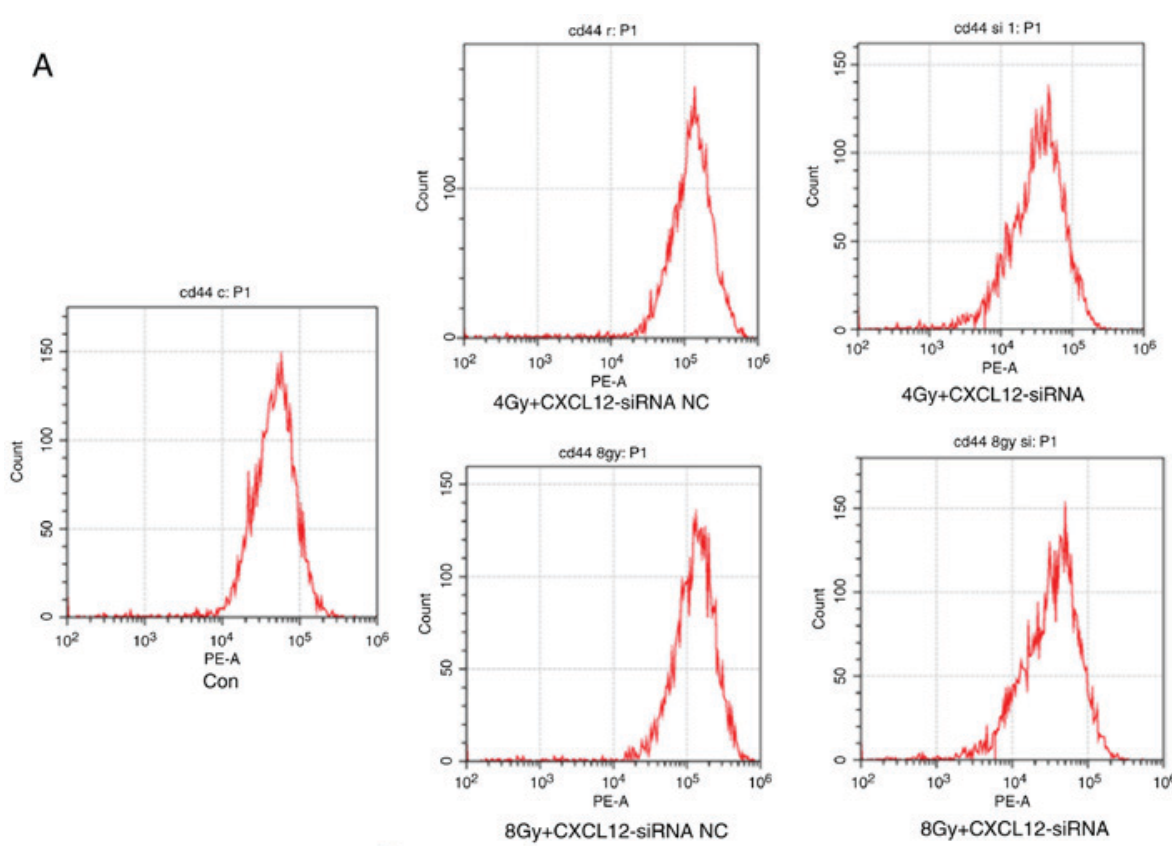

B
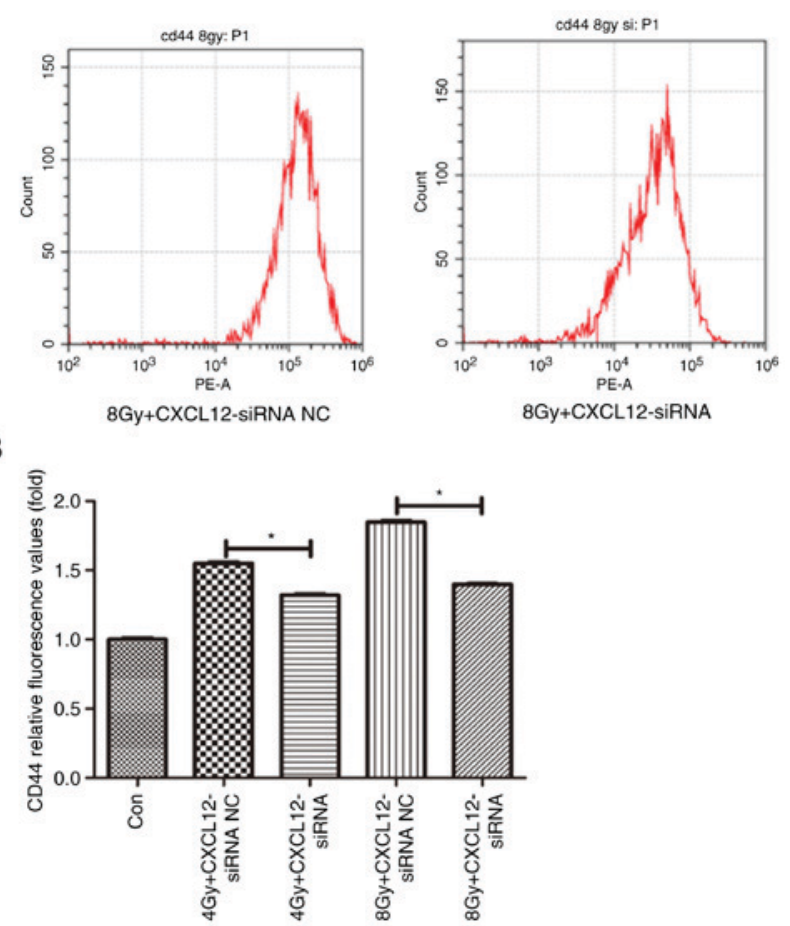

Figure 4. Inhibition of CXCL12 downregulates the expression level of CD44 in irradiated Hela cells. (A) CD44 fluorescence data in irradiated cells treated with or without CXCL12 siRNA was collected and (B) presented. Data are presented as the mean \pm standard deviation. $n=3$. "P $<0.05$. CXCL12, stromal cell-derived factor 1; CD44, CD44 antigen; siRNA, small interfering RNA; NC, negative control; Con, control; PE, phycoerythrin. 

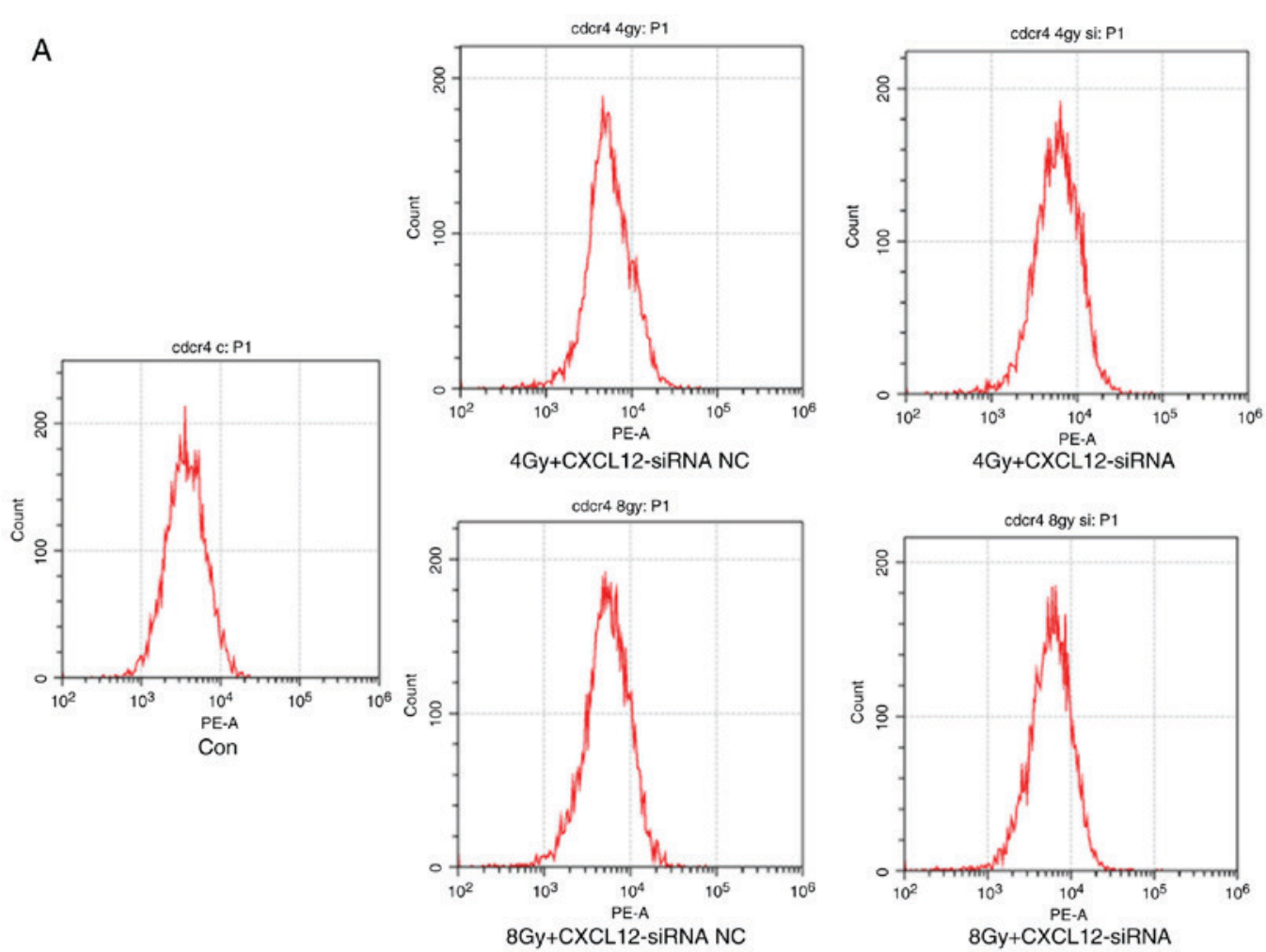

B

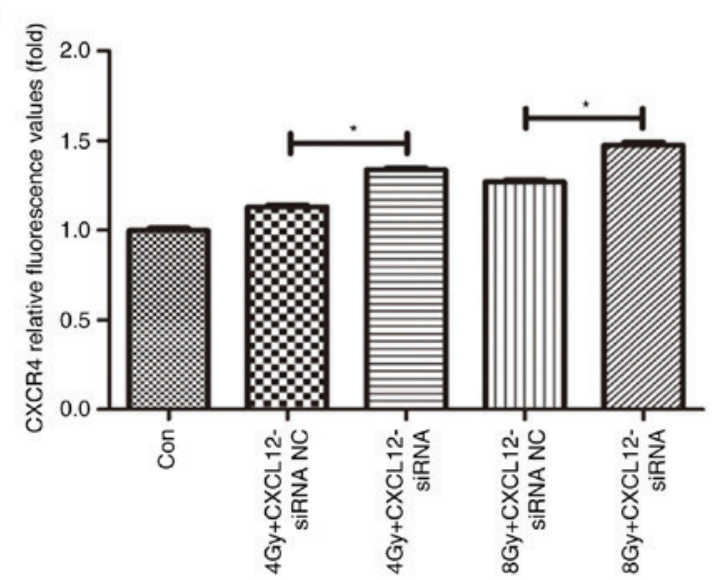

Figure 5. Inhibition of CXCL12 upregulates the expression level of CXCR4 in irradiated Hela cells. (A) CXCR4 fluorescence data in irradiated cells treated with or without CXCL12 siRNA was collected and (B) presented. Data are presented as the mean \pm standard deviation. $n=3$. "P<0.05. CXCL12, stromal cell-derived factor 1; CD44, CD44 antigen; siRNA, small interfering RNA; NC, negative control; Con, control; CXCR4, C-X-C chemokine receptor type 4; PE, phycoerythrin.

resistance to radiotherapy in different cancer types $(11,12)$. Accordingly, the function of CXCL12 was investigated to examine the mechanism of radioresistance in cervical cancer.

The chemokine CXCL12 (17) is an important $\alpha$-chemokine that binds primarily to its cognate receptor CXCR4 (18-20). Experimentally, the activation of the CXCL12/CXCR4 axis has been demonstrated to serve an important role in tumor growth, invasion and metastasis (21-25). Zhang et al (26) observed that CXCL12 was able to activate protein kinase B (AKT), and upregulate the expression level of vascular endothelial growth factor in breast cancer cells. Barbero et al (27) demonstrated that activation of the CXCL12/CXCR4 axis was able to initiate the ERK1/2 and AKT signaling pathways, inducing the proliferation of glioma cells. Previous studies demonstrated that the CXCL12/CXCR4 axis was mediated by
CD44. Avigdor et al (28) reported that CD44 and hyaluronic acid cooperate with CXCL12 in the trafficking of human CD34 ${ }^{+}$ stem/progenitor cells to bone marrow. Fuchs et al (10) identified that CXCL12-induced CXCR4 signaling regulates cell motility and angiogenesis in tumors in a CD44-dependent manner.

In the present study, RNA interference with siRNA was used to downregulate the expression level of CXCL12 in Hela cells. To examine the function of CXCL12 in Hela cells, cell viability and apoptosis were determined at $24 \mathrm{~h}$ post-irradiation. The present results demonstrated that cell viability was decreased and apoptosis was induced following treatment with CXCL12 siRNA with radiation. In a previous study, it was observed that CXCL12 was upregulated in cervical cancer (29). Therefore, it was hypothesized that CXCL12 is involved in the radioresistance of cervical cancer. However, 
the effects of upregulation of CXCL12 on radioresistance were not evaluated, which is a limitation of the present study. In addition, the use of a cell viability assay $24 \mathrm{~h}$ post-irradiation, although it may provide an indication of radiation response, is a relatively early time point and may largely reflect a cytostatic response. Cell survival assays require investigation in future studies.

The present study demonstrated that the expression level of CD44 in Hela cells was downregulated with the inhibition of CXCL12. CD44 is a ubiquitous multistructural and multifunctional cell surface adhesion molecule involved in cell-cell and cell-matrix interactions. Faber et al (30) reported that the CXCL12-CXCR4 axis may be a key pathway in the interaction between cancer stem cells and their surrounding supportive cells in the cancer stem cell niche. CXCL12 induces cytoskeleton reorganization and pseudopod formation in tumor cells, which was hypothesized to be involved in the adhesion of tumor stem cells to the microenvironment (31). This suggests that CXCL12 exerts effects by affecting the tumor environment.

CXCR4 is the receptor of CXCL12 (30). In the present study, it was identified that the expression level of CXCR4 was increased with the inhibition of CXCL12. In the microarray analysis in our previous study, the upregulation of CXCR4 was not observed (8). It is hypothesized that the upregulation of CXCR4 occurs as a response to the decrease in CXCL12. Although the sensitivity of CXCR4 to CXCL12 was increased, the CXCL12/CXCR4 axis remained inhibited.

In conclusion, CXCL12/CXCR4 axis activation is critical to radioresistance in cervical cancer. CD44 may additionally be involved in the process. In future studies, further examination of the mechanisms of the CXCL12/CXCR4 axis in radioresistance is required to clarify the effects of the tumor environment on radioresistance and develop novel therapeutic strategies for cervical cancer.

\section{Acknowledgements}

Not applicable.

\section{Funding}

No funding was received.

\section{Availability of data and materials}

The datasets used and/or analyzed during the current study are available from the corresponding author on reasonable request.

\section{Authors' contributions}

$\mathrm{HH}$ and FW conceived and designed the study. PZ analyzed and interpreted the data. ZF wrote the manuscript and performed the statistical analysis. HL and FW assisted with the data interpretation and critically reviewed the manuscript. All authors read and approved the final manuscript.

\section{Ethics approval and consent to participate}

Not applicable.

\section{Patient consent for publication}

Not applicable.

\section{Competing interests}

The authors declare that they have no competing interests.

\section{References}

1. Sun C, Reimers LL and Burk RD: Methylation of HPV16 genome $\mathrm{CpG}$ sites is associated with cervix precancer and cancer. Gynecol Oncol 121: 59-63, 2011.

2. Hu SY, Zheng RS, Zhao FH, Zhang SW, Chen WQ and Qiao YL: Trend analysis of cervical cancer incidence and mortality rates in Chinese women during 1989-2008. Zhongguo Yi Xue Ke Xue Yuan Xue Bao 36: 119-25, 2014 (In Chinese).

3. Jiang P, Liu J, Li W, Zeng X and Tang J: Role of p53 and p21 polymorphisms in the risk of cervical cancer among Chinese women. Acta Biochim Biophys Sin (Shanghai) 42: 671-676, 2010.

4. Zhang B, Chen J, Ren Z, Chen Y, Li J, Miao X, Song Y, Zhao T, Li Y, Shi Y, et al: A specific miRNA signature promotes radioresistance of human cervical cancer cells. Cancer Cell Int 13: 118 , 2013.

5. Thompson RF and Maity A: Radiotherapy and the tumor microenvironment: Mutual influence and clinical implications. Adv Exp Med Biol 772: 147-165, 2014.

6. Shinohara ET and Maity A: Increasing sensitivity to radiotherapy and chemotherapy by using novel biological agents that alter the tumor microenvironment. Curr Mol Med 9: 1034-1045, 2009.

7. Hanahan D and Weinberg RA: Hallmarks of cancer: The next generation. Cell 144: 646-674, 2011.

8. Fu ZC, Wang FM and Cai JM: Gene expression changes in residual advanced cervical cancer after radiotherapy: Indicators of poor prognosis and radioresistance? Med Sci Monit 21: 1276-1287, 2015.

9. Dubrovska A, Elliott J, Salamone RJ, Telegeev GD, Stakhovsky AE, Schepotin IB, Yan F, Wang Y, Bouchez LC, Kularatne SA, et al: CXCR4 expression in prostate cancer progenitor cells. PLoS One 7: e31226, 2012.

10. Fuchs K, Hippe A, Schmaus A, Homey B, Sleeman JP and Orian-Rousseau V: Opposing effects of high- and low-molecular weight hyaluronan on CXCL12-induced CXCR4 signaling depend on CD44. Cell Death Dis 4: e819, 2013.

11. Goffart N, Lombard A, Lallemand F, Kroonen J, Nassen J, Di Valentin E, Berendsen S, Dedobbeleer M, Willems E, Robe $\mathrm{P}$, et al: CXCL12 mediates glioblastoma resistance to radiotherapy in the subventricular zone. Neuro Oncol 19: 66-77, 2017.

12. Wang D, Jiao C, Zhu Y, Liang D, Zao M, Meng X, Gao J, He Y, Liu W, Hou J, et al: Activation of CXCL12/CXCR4 renders colorectal cancer cells less sensitive to radiotherapy via up-regulating the expression of survivin. Exp Biol Med (Maywood) 242: 429-435, 2017.

13. Davis S, Lollo B, Freier S and Esau C: Improved targeting of miRNA with antisense oligonucleotides. Nucleic Acids Res 34: 2294-2304, 2006.

14. Livak KJ and Schmittgen TD: Analysis of relative gene expression data using real-time quantitative PCR and the 2(-Delta Delta C(T)) method. Methods 25: 402-408, 2001.

15. Barker HE, Paget JT, Khan AA and Harrington KJ: The tumour microenvironment after radiotherapy: Mechanisms of resistance and recurrence. Nat Rev Cancer 15: 409-425, 2015.

16. Zips D, Eicheler W, Brüchner K, Jackisch T, Geyer P, Petersen C, van der Kogel AJ and Baumann M: Impact of the tumour bed effect on microenvironment, radiobiological hypoxia and the outcome of fractionated radiotherapy of human FaDu squamous-cell carcinoma growing in the nude mouse. Int $\mathbf{J}$ Radiat Biol 77: 1185-1193, 2001.

17. Egeblad M and Werb Z: New functions for the matrix metalloproteinases in cancer progression. Nat Rev Cancer 2: 161-174, 2002.

18. Tachibana $\mathrm{K}$, Hirota $\mathrm{S}$, Iizasa $\mathrm{H}$, Yoshida H, Kawabata $\mathrm{K}$, Kataoka Y, Kitamura Y, Matsushima K, Yoshida N, Nishikawa S, et al: The chemokine receptor CXCR4 is essential for vascularization of the gastrointestinal tract. Nature 393: 591-594, 1998. 
19. Dorsam RT and Gutkind JS: G-protein-coupled receptors and cancer. Nat Rev Cancer 7: 79-94, 2007.

20. Takakura N, Watanabe T, Suenobu S, Yamada Y, Noda T, Ito Y Satake M and Suda T: A role for hematopoietic stem cells in promoting angiogenesis. Cell 102: 199-209, 2000.

21. Park HJ, Griffin RJ, Hui S, Levitt SH and Song CW: Radiation-induced vascular damage in tumors: Implications of vascular damage in ablative hypofractionated radiotherapy (SBRT and SRS). Radiat Res 177: 311-327, 2012.

22. Boimel PJ, Smirnova T, Zhou ZN, Wyckoff J, Park H, Coniglio SJ, Qian BZ, Stanley ER, Cox D, Pollard JW, et al: Contribution of CXCL12 secretion to invasion of breast cancer cells. Breast Cancer Res 14: R23, 2012.

23. Burns JM, Summers BC, Wang Y, Melikian A, Berahovich R, Miao Z, Penfold ME, Sunshine MJ, Littman DR, Kuo CJ, et al: A novel chemokine receptor for SDF-1 and I-TAC involved in cell survival, cell adhesion, and tumor development. J Exp Med 203: 2201-2213, 2006.

24. Burger JA and Kipps TJ: CXCR4: A key receptor in the crosstalk between tumor cells and their microenvironment. Blood 107: 1761-1767, 2006.

25. Kucia M, Reca R, Miekus K, Wanzeck J, Wojakowski W, Janowska-Wieczorek A, Ratajczak J and Ratajczak MZ: Trafficking of normal stem cells and metastasis of cancer stem cells involve similar mechanisms: Pivotal role of the SDF-1-CXCR4 axis. Stem Cells 23: 879-894, 2005.
26. Zhang XH, Jin X, Malladi S, Zou Y, Wen YH, Brogi E, Smid M, Foekens JA and Massagué J: Selection of bone metastasis seeds by mesenchymal signals in the primary tumor stroma. Cell 154: 1060-1073, 2013.

27. Barbero S, Bonavia R, Bajetto A, Porcile C, Pirani P, Ravetti JL, Zona GL, Spaziante R, Florio T and Schettini G: Stromal cell-derived factor 1alpha stimulates human glioblastoma cell growth through the activation of both extracellular signal-regulated kinases 1/2 and Akt. Cancer Res 63: 1969-1974, 2003.

28. Avigdor A, Goichberg P, Shivtiel S, Dar A, Peled A, Samira S, Kollet O, Hershkoviz R, Alon R, Hardan I, et al: CD44 and hyaluronic acid cooperate with SDF-1 in the trafficking of human CD34+ stem/progenitor cells to bone marrow. Blood 103: 2981-2989, 2004.

29. Huang Y, Zhang J, Cui ZM, Zhao J and Zheng Y: Expression of the CXCL12/CXCR4 and CXCL16/CXCR6 axes in cervical intraepithelial neoplasia and cervical cancer. Chin J Cancer 32: 289-296, 2013

30. Faber A, Goessler UR, Hoermann K, Schultz JD, Umbreit C and Stern-Straeter J: SDF-1-CXCR4 axis: Cell trafficking in the cancer stem cell niche of head and neck squamous cell carcinoma. Oncol Rep, 29: 2325-2331, 2013.

31. Müller A, Homey B, Soto H, Ge N, Catron D, Buchanan ME McClanahan T, Murphy E, Yuan W, Wagner SN, et al: Involvement of chemokine receptors in breast cancer metastasis. Nature 410: 50-56, 2001. 